\title{
BALANCED SCORECARD NA GESTÃO E FISCALIZAÇÃO DE CONTRATOS DE SERVIÇOS NA ÁREA PÚBLICA
}

\section{ARTIGO ORIGINAL}

MATTOS, Solange Maria Da Silva Nunes ${ }^{1}$, LEPSCH, Miriam Assunção De Souza ${ }^{2}$, MIZRAHI, Márcia Ester ${ }^{3}$

MATTOS, Solange Maria Da Silva Nunes. LEPSCH, Miriam Assunção De Souza. MIZRAHI, Márcia Ester. Balanced scorecard na gestão e fiscalização de contratos de serviços na área pública. Revista Científica Multidisciplinar Núcleo do Conhecimento. Ano 06, Ed. 06, Vol. 09, pp. 61-82. Junho de 2021. ISSN: 24480959, Link de acesso:

https://www.nucleodoconhecimento.com.br/administracao/area-publica, DOI: 10.32749/nucleodoconhecimento.com.br/administracao/area-publica

\section{RESUMO}

A presente pesquisa tem como objetivo geral apresentar as possibilidades de contribuição do Balanced Scorecard (BSC) na gestão e fiscalização de contratos de serviços na área pública, através de um estudo de caso do Instituto Nacional de Câncer José de Alencar Gomes da Silva - INCA. Este trabalho tem caráter exploratório e aplicado. A metodologia utilizada seguiu uma abordagem qualitativa, fundamentada em levantamento bibliográfico, pesquisa documental e estudo de caso. Para tal, foi analisado o setor de Apoio Administrativo ligado a Coordenação

1 Mestre em Ciência Ambiental e especialista em Políticas Públicas e Gestão Governamental pela Universidade Federal Fluminense - UFF. Bacharel em Ciências Econômicas pela Universidade Federal do Paraná - UFPR.

2 Doutora em Ciências Empresariais pela Universidad del Museo Social Argentino (UMSA) e graduada em Ciências Contábeis pela Universidade Federal do Rio de Janeiro (UFRJ).

3 Mestre em Administração pela Universidade Federal Fluminense (UFF), Pós graduada em Administração Pública pela Fundação Ceperj e graduada em Turismo pela UFF.

RC: 88625

Disponível em: https://www.nucleodoconhecimento.com.br/administracao/area-publica 
de Administração Geral do INCA, através da matriz SWOT (ou FOFA), as forças, fraquezas, oportunidades e ameaças. Posteriormente, foi elaborado sob a ótica do BSC indicadores de desempenho possíveis de serem utilizados pelos gestores de contratos de serviços continuados. Verificou-se que o BSC tem papel importante num modelo de gestão baseado em constante aprendizado, sendo uma ferramenta capaz de sistematizar a discussão, vislumbrando um processo continuo de aperfeiçoamento para essa área do Instituto.

Palavras-chave: Balanced Scorecard, Administração Pública, Gestão e Fiscalização de Contratos, INCA.

\section{INTRODUÇÃO}

A Administração Pública, nas últimas décadas, entendeu a necessidade de avaliar seus resultados e demonstrar maior transparência à sociedade. Resultando numa busca por melhoria do seu desempenho para atender seus usuários. Freitas (2016) observa que órgãos públicos se voltaram para as técnicas, metodologias e mecanismos de gestão utilizados em instituições privadas. Diversas instituições públicas têm estudado e implantado novas formas de gestão estratégica, uma vez que, também, nesse setor, o foco da otimização do uso de recursos tem sido uma necessidade preponderante.

Em tempos de crise, com a crescente pressão sobre as organizações públicas em atender melhor a sociedade e realizar mais investimentos com menos recursos disponíveis, a implementação da gestão integrada e do planejamento estratégico podem ser importante oportunidade para a redução de custos, melhoria da qualidade e alcance dos resultados dessas organizações.

Não obstante, a utilização de instrumentos do planejamento estratégico contribui para o enfrentamento da crise causada pela COVID-19 e para os desafios de saúde atuais, assim como para a recuperação do mundo após a pandemia. $O$ fortalecimento do setor de saúde, da economia e dos setores produtivos, pode ser parte integrante de estratégias dos governos.

Segundo Moreira; Sedrani e Lima (2005), o Balanced Scorecard (BSC) é mais que um instrumento para medir desempenho, representa um Sistema de Gestão Estratégica cujo principal diferencial é reconhecer que apenas os indicadores financeiros não são suficientes para avaliar o desempenho da organização. Nesse cenário, surge a seguinte questão de pesquisa: de que forma o Balanced Scorecard (BSC) pode ser um instrumento de auxílio para a otimização da gestão e fiscalização de contratos de serviços no Setor Público?

Apesar da vertente acadêmica da pesquisa, esse é um tema de interesse social e econômico. Tendo em vista as recentes preocupações com os resultados no setor 
público, agravada neste momento, em decorrência da crise causada pela pandemia da Covid-19, afetando diretamente as organizações e entidades da área de saúde. Assim a relevância do estudo se apresenta pela possibilidade de contribuições para a melhoria e otimização de resultados na gestão de recursos públicos.

Nesse contexto, o presente trabalho tem como objetivo geral apresentar as possibilidades de contribuição do Balanced Scorecard (BSC) na gestão e fiscalização de contratos de serviços na área pública, através de um estudo de caso do Instituto Nacional de Câncer José de Alencar Gomes da Silva - INCA.

\section{REVISÃO DA LITERATURA}

\subsection{PLANEJAMENTO ESTRATÉGICO E GESTÃO PÚBLICA}

O pensamento estratégico carrega a fundamentação necessária aos gestores para a elaboração de um modelo e utilização de ferramentas capazes de fornecer maior efetividade na gestão das organizações públicas ou privadas. Vivemos uma época de mudanças rápidas e transformações profundas, portanto, é importante que as organizações adotem o pensamento estratégico como um instrumento para orientar seu modelo de gestão (ZAJDSNAJDER, 1989).

Ao inverso do que se poderia cogitar, são nos momentos de amplas mudanças que o planejamento se torna ainda mais importante. E tais mudanças não se limitam ao universo empresarial. As demandas por um Estado mais eficiente, flexível, democrático e efetivo nas suas ações são cada vez mais respeitadas. Tais demandas não podem ser respondidas com a improvisação e, por esse motivo, o planejamento e a gestão, bem como o uso de ferramentas eficientes para a sua realização, tornam-se exigências básicas (ZIMMERMAN, 2015).

De acordo com Matus (1988), planejamento está ligado à ideia de preparar o futuro a partir do momento atual, refletindo sobre a situação a ser enfrentada e os objetivos a atingir. Para Lobato (2000), é o planejamento que determina a forma para a tomada de decisões, com a finalidade de sustentar o sucesso da organização no seu ambiente de atuação atual e futuro.

Segundo Pinto (1982) o planejamento é um processo racional que intervém na realidade atual para atingir uma situação futura desejada. Não obstante, este processo integra decisões que formaliza a estratégia em busca da produção de um resultado articulado. Ou seja, é o controle do futuro da organização por meio de análise racional (MINTZBERB et al., 2000).

Na visão de Prahalad e Hamel (2005), as ações pensadas no presente almejando obter oportunidades no futuro é chamada de estratégia. Para tal, ela determina os meios para o domínio das competências necessárias a fim de alcançar os objetivos

RC: 88625

Disponível em: https://www.nucleodoconhecimento.com.br/administracao/area-publica 
traçados. Segundo estes autores, a estratégia supera o arranjo entre metas e recursos, ela é formulada para instigar os funcionários a superarem metas aparentemente inalcançáveis, bem como contornarem de forma criativa as limitações de recursos.

A estratégia não é um procedimento gerencial desconexo, mas sim um processo contínuo. Inicia-se no sentido mais amplo, com a missão da organização que deve ser desenvolvida para que as ações individuais sejam niveladas a ela e que lhe proporcionem apoio. O sistema gerencial deve assegurar a eficácia dessa explanação. A estratégia deve ser vista como um processo contínuo que movimenta a organização através da declaração da missão de alto nível para os empregados na linha de frente de ação (KAPLAN; NORTON, 2006, p 84).

Drucker (1998) pondera que o planejamento estratégico ao esquematizar as ações atuais com vistas ao futuro tem um risco envolvido em cada decisão. Neste sentido, a realimentação do processo ocorre de forma organizada e sistematizada, o que permite medir o resultado das decisões, minimizando os riscos.

Segundo Ackoff (1976), o planejamento pode ser dividido em três níveis: estratégico, tático e operacional. O planejamento estratégico formula um plano de visão geral para a organização visando o crescimento a longo prazo. O planejamento tático é a distribuição das metas de maneira mais pormenorizada para cada departamento no médio prazo, para assim avaliar o desempenho da organização com foco na eficiência. Finalmente, o planejamento operacional monitora as ações do dia a dia focada no curto prazo.

Podemos dizer que o planejamento estratégico é um esforço disciplinado para a produção de decisões e ações que modelam e guiam o que uma organização é, faz e por que o faz. Neste sentido, o objetivo principal do planejamento estratégico é o desenvolvimento de um pensamento estratégico que crie valor para o cliente ou consumidor final.

A administração estratégica não é mais utilizada de forma exclusiva por empresas privadas. Em função das mudanças na economia mundial, novas conjunturas sociopolíticas surgiram. As esferas públicas passaram a adotar este instrumento com mais frequência na sua gestão, com o intuito de obter ganhos de tempo, efetividade nas ações e melhora nas entregas a sociedade. Da mesma forma, os cidadãos tornam-se mais exigentes quanto a qualidade dos serviços ofertados. Portanto, é necessário organizações públicas mais flexíveis e inovadoras buscando satisfazer as demandas do usuário (SOUZA; REZENDE E HARDT, 2007). 


\subsection{BALANCED SCORECARD ADAPTADO AO SETOR PÚBLICO}

O Balanced Scorecard (BSC) é uma ferramenta estratégica criado em 1992 por dois professores da Harvard Business School, Robert Kaplan e David Norton. De acordo com os autores, ao longo de muito tempo os resultados financeiros foram exclusivamente utilizados como indicadores pelas organizações para avaliarem sua gestão. Contudo, com o acirramento da competitividade do mercado e o aumento da exigência dos consumidores, novas demandas foram impostas às empresas e governos. Doravante, para obter resultados positivos tornou-se necessários integrar diversas áreas da organização através do planejamento estratégico. Representando uma revolução no conceito tradicional de pensar estrategicamente (ZIMMERMAN, 2015).

Conforme Kaplan e Norton (1997) a aplicação do BSC e de seus indicadores requer a adoção de estratégias embasadas em indicadores balanceados em quatro perspectivas: financeira, clientes, processos internos e aprendizado e crescimento. O BSC acabou ganhando grande importância entre as organizações públicas e privadas, por ser mais que um sistema de indicadores ou um auxiliar na implantação da estratégia. O BSC pode ser considerado atualmente um sistema de gestão estratégica que utiliza indicadores financeiros e não financeiros, esclarecendo relações de causa e efeito entre a visão, os objetivos e as inciativas estratégicas (MENDES, 2015).

O BSC é um grupo de medidas selecionadas que se originam da estratégia de uma organização. Essas medidas são informações que a gerência ou direção utiliza para comunicar aos funcionários e outros interessados os resultados de desempenho através dos quais a organização atingirá a sua missão e seus objetivos estratégicos. Ajuda as organizações a medir o desempenho organizacional e implementar a estratégia com êxito (NIVEN, 2005).

Para Kraemer (2004), o BSC é um conjunto de indicadores que proporciona rápida e abrangente visão do desempenho empresarial sob diferentes perspectivas. Baseiase em um mapa estratégico de informações, onde se torna possível visualizar e acompanhar as metas e objetivos da empresa, tendo como diferencial representar o equilíbrio entre os indicadores internos e externos à organização.

As características do BSC estão relacionadas entre si, cada uma das quatro perspectivas é interligada por uma cadeia de relações de causa e efeito. São elas: perspectiva de aprendizado e crescimento, perspectivas dos processos internos, perspectiva dos clientes e, por fim, perspectiva financeira ou orçamentária (KAPLAN e NORTON, 2006, p. 7). 
A figura 1 permite visualizar as quatro perspectivas que formam o esquema elaborado por Kaplan e Norton, bem como sua integração com a visão e a estratégia num sistema interligado e conectado.

Figura 1 - Representação da integração de indicadores de desempenho baseado no BSC.

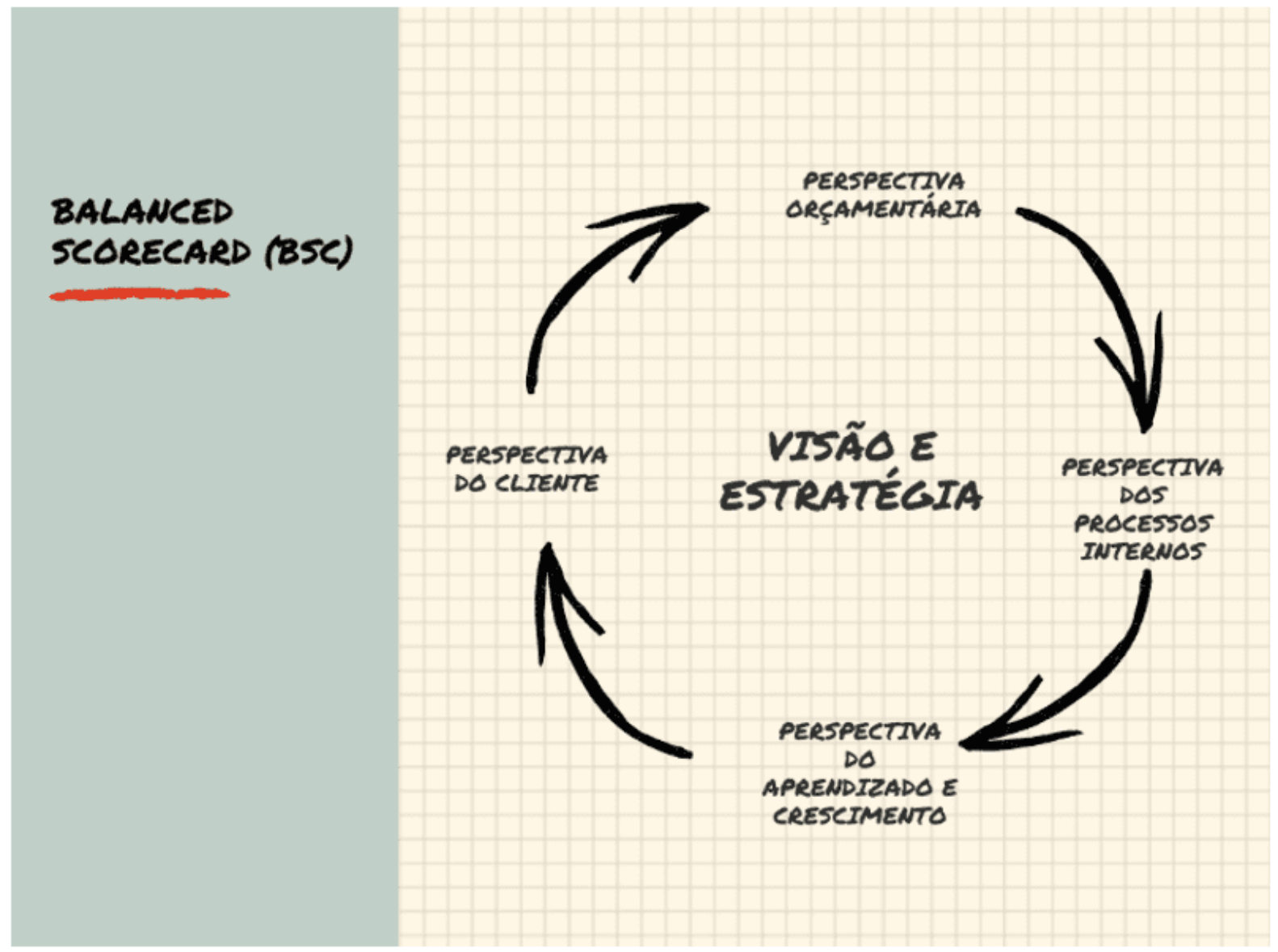

Fonte: adaptado de Kaplan e Norton (1997).

Kaplan e Norton (1997) destacam os benefícios do BSC como um instrumento flexível, capaz de promover um monitoramento contínuo do planejamento estratégico. Os indicadores da estratégia podem ser alinhados com os objetivos da organização. Além disso, considera diversos grupos e interesses na execução da estratégia vinculando ao planejamento. Por fim comunica a estratégia e possibilita o direcionamento e enfoque nas ações.

A metodologia BSC nasceu no ambiente de empresas privadas, por este motivo, deve haver uma adaptação desta metodologia quando transferida ao contexto de instituições do setor público, uma vez que são realidades completamente diferentes. Somente os indicadores financeiros não demonstram se a organização está

RC: 88625

Disponível em: https://www.nucleodoconhecimento.com.br/administracao/area-publica 
cumprindo sua missão, pois para entidades governamentais o papel social é muito mais importante.

Meirelles (2004, p. 84) diferencia a administração particular da administração pública com base no seguinte critério: será administração particular se os bens e interesses geridos são individuais; será administração pública quando os bens e interesses são da coletividade. Aponta que cabe a administração pública a gestão de bens e interesses da sociedade em todas as esferas do governo, seguindo preceitos do direito e da moral visando o bem comum.

O entendimento da missão e da estratégia é facilitada pelo BSC de uma unidade da organização, em consonância, os objetivos tornam-se tangíveis. O BSC pode começar com objetivos restritos e depois ser levado a toda organização, deixando de ser um sistema de indicadores e passando a compor um sistema maior de gestão estratégica (KAPLAN e NORTON, 1997).

Trosa (2001) destaca que as organizações em geral passam por ajustes em relação a realidade atual, marcada por transformações tecnológicas e sociais mais dinâmicas e sem fronteiras geográficas. Na medida que os órgãos públicos buscam aprimorar sua prestação de serviço à sociedade, o BSC vem se constituindo como ferramenta de gestão neste setor. Com o advento da era da informação, a eficiente alocação dos ativos tangíveis tem se mostrado insuficiente para obter e manter vantagens competitivas (GALAS e PONTE, 2006). Em decorrência disso, é favorável uma gestão estratégica centrada nos ativos intangíveis (KAPLAN e NORTON, 1997).

Marques (2003) demonstra que as organizações públicas não são obrigadas a adotar as quatro perspectivas genéricas do BSC: aprendizado e crescimento, processos internos, cliente e finanças. O mais relevante é a aplicação da metodologia. Adotando um sistema enxuto de medição, que reflete as diretrizes e o posicionamento estratégico da organização, e que por fim torne a gestão integrada.

\subsection{TERCEIRIZAÇÃO NO SERVIÇO PÚBLICO}

As organizações públicas e privadas perceberam que para reduzir custos e tornar seus serviços e produtos mais competitivos no mercado teriam que focar na execução de sua atividade fim. Para que isso aconteça é necessário delegar para terceiros as atividades consideradas de apoio. Desta forma, a terceirização vem se expandindo de forma significativa, reflexo da necessidade de adaptação a um mercado em constante transformação (DAHER, 2016).

No Brasil, a execução indireta dos serviços na Administração Pública tornou-se um marco regulatório com a elaboração do Decreto-lei $n^{\circ} 200 / 1976$, que inicialmente utilizou-se deste recurso com o objetivo de impedir o crescimento exagerado da 
máquina pública. Neste sentindo, a Administração Pública, com o intuito de reduzir seu tamanho e restringindo a realização de concursos públicos para ingresso de novos servidores públicos buscou na terceirização de serviços uma forma de atender o aumento da demanda da sociedade por serviços públicos (DE FREITAS e MALDONADO, 2013).

A terceirização atualmente é um recurso bastante utilizado na gestão estratégica. Tanto no setor público quanto no privado, a transferência de certas atividades que não pertencem à atividade-fim do negócio para fornecedores terceiros, mais especializados e melhor inclusos tecnologicamente nesta atividade, proporciona ao contratante ganhos em escala e eficiência que não seriam possíveis caso tratassem eles próprios dessa função. A redução de custos é um ganho que se pode observar com esta estratégia levando a uma competitividade maior junto aos concorrentes.

No setor público não deve ser diferente. Focando em sua atividade-fim e transferindo tarefas que não está ligada ao seu objetivo final a empresas especializadas obtendo maior eficiência financeira e entregando a população um produto de melhor qualidade. No entanto, para que o processo de terceirização ocorra de forma eficiente dentro de um negócio, este deve ser parte de um planejamento estratégico da instituição e que leve em conta em sua implantação fatores que não se resumam a redução de custos em si, mas também em melhoria, agilização e aumento da qualidade dos serviços.

\subsection{GESTÃO E FISCALIZAÇÃO DE CONTRATOS}

À Administração Pública, observado o direito e a obrigação legal, compete acompanhar e fiscalizar os contratos firmados com objetivo de garantir que o objeto contratado seja prestado adequadamente pelas empresas contratadas. Neste sentido, o ato de gerenciar e fiscalizar contratos na área pública é regulamentado pelo artigo 37, inciso XXI da Constituição Federal, que institui normas para licitações e contratos da Administração Pública e dá outras providências.

Especificamente, com base nos contratos de serviços, a Portaria do Tribunal de Contas da União - TCU no 297/2012 afirma que a fiscalização de contrato de serviço terceirizado é o "conjunto de procedimentos destinados à verificação da conformidade da prestação dos serviços e da alocação dos recursos necessários, com objetivo de assegurar o cumprimento do objeto contratado".

Atualmente, as "regras de contratação de serviços sob o regime de execução indireta no âmbito da Administração Pública federal, direta, autárquica e fundacional foram definidas pela Secretaria de Gestão do Ministério do Planejamento, Desenvolvimento e Gestão" através da Instrução Normativa n 05, de 26 de maio de 2017 (OLIVEIRA, 2017). A norma define o que são serviços contínuos e não continuados. 
Esta pesquisa está focada nos serviços prestados de forma contínua, que por sua vez visam atender à necessidade pública de forma permanente, assegurando o funcionamento das atividades finalísticas do órgão ou o cumprimento da missão institucional (artigo 15, IN/MPDG 05/2017). As atividades que são, de preferência, objeto de execução indireta são: conservação, limpeza, vigilância, transportes, informática, recepção, telecomunicações e manutenção de prédios, equipamentos e instalações (DAHER, 2016). A contratação dos serviços de que trata a IN/MPDG no 05/2017 serão realizados observando o planejamento da contratação, a seleção dos fornecedores e a gestão do contrato.

Além da parte burocrática na execução do processo de fiscalização, surgem problemas jurídicos, ocasionados pela subordinação direta e o vínculo empregatício. A fim de que os riscos sejam reduzidos e o processo de terceirização seja efetivo, a gestão de contratos dos serviços terceirizados é uma prática necessária a gestão estratégica (FERNANDES e CARVALHO NETO, 2005).

\section{METODOLOGIA}

Para alcançar os objetivos propostos a metodologia utilizada seguiu uma abordagem qualitativa, baseada em revisão bibliográfica, pesquisa documental e estudo de caso. A pesquisa bibliográfica foi desenvolvida com base em material publicado em livros, revistas, dissertações e artigos sobre o assunto. A análise documental foi realizada a partir dos relatórios de gestão, plano estratégico e informações disponíveis no site da instituição. O trabalho pode ser considerado um estudo de caso, pois está alinhado à observação feita por Yin (2001), na qual o autor afirma que como estratégia de pesquisa, utiliza-se o estudo de caso em muitas situações, dentre as quais se incluem os estudos organizacionais, gerenciais e pesquisa em administração pública.

O presente trabalho tem caráter exploratório, pois objetiva fornecer uma visão ampla sobre um fato quando o assunto é pouco estudado (Gil, 2008). A pesquisa é aplicada porque está fundamentada na necessidade de resolver um problema concreto ao contribuir para o debate acerca da possibilidade de se adaptar a ferramenta de gestão estratégica o Balanced Scorecard à realidade de uma gestão pública (Vergara, 2016). O INCA foi escolhido como campo de estudo pois utiliza o planejamento estratégico como instrumento para aprimorar a gestão, buscando a excelência nos serviços prestados à população. 


\section{RESULTADOS E DISCUSSÃO}

\subsection{CARACTERIZAÇÃO DA INSTITUIÇÃO}

O Instituto Nacional de Câncer José Alencar Gomes da Silva (INCA) é um órgão subordinado ao Ministério da Saúde e maior instituição pública de referência na área da Oncologia do Brasil. Atua em diversas áreas como Assistência, Pesquisa, Ensino, Prevenção e Vigilância, e sua missão é promover o controle do câncer com ações nacionais integradas em prevenção, assistência, ensino e pesquisa (Relatório de gestão INCA, 2019).

Segundo o Plano estratégico do INCA 2020-2023, a organização é considerada uma "Instituição de Ciência e Tecnologia (ICT), conforme a Lei no 8.691, de 28 de julho de 1993, cujos principais objetivos são a promoção e a realização de pesquisa e do desenvolvimento científico e tecnológico do País". Constitui-se ainda como um Centro de Assistência de Alta Complexidade em Oncologia (Cacon), conforme Portaria SAES/MS no 1.399, de 17 de dezembro de 2019, que redefine os critérios e padrões de referência para habilitar os estabelecimentos de saúde de alta complexidade em oncologia no SUS.

O INCA é um órgão público da administração direta e, como unidade integrante da Secretaria de Atenção Especializada em Saúde (SAES), organiza seu planejamento em consonância com o Planejamento Estratégico do Ministério da Saúde e com o Plano Plurianual (PPA) do governo. Essa premissa permite que o planejamento tenha como base a capacidade operacional e financeira do Instituto, tornando factível a sua concretização (Relatório de gestão INCA, 2019; pg. 29).

De acordo com a Portaria MS/GM no 1.419, de 8/6/2017, à Coordenação de Administração-Geral (COAGE) compete planejar, orientar, coordenar e controlar a execução das atividades de apoio administrativo operacional; contratos e convênios; suprimentos; orçamento e finanças; patrimônio; infraestrutura e engenharia clínica. Tais competências envolvem o desenvolvimento, a implantação, o aperfeiçoamento e a otimização de projetos e processos, programas e políticas de gestão de recursos financeiros e materiais.

Além disso, compete a essa Coordenação participar da elaboração do planejamento organizacional, de seu desenvolvimento e da proposição de estratégias. $O$ trabalho desenvolvido pela COAGE está em consonância com o objetivo estratégico do INCA referente à gestão para o período 2016-2019, que é aprimorar processos e instrumentos de gestão para maior eficiência das ações de controle do câncer.

A missão institucional do Setor de Serviço de Apoio Administrativo é assegurar a supervisão, controle e orientação das atividades relativas à área administrativa do INCA, de acordo com as normas técnicas e as legislações vigentes estabelecidas

RC: 88625

Disponível em: https://www.nucleodoconhecimento.com.br/administracao/area-publica 
pelos órgãos públicos e em conformidade com as especificações técnicas inerentes, desenvolvendo trabalhos de apoio técnico-administrativo, rotinas, procedimentos, sistemas e administração geral, avaliando a qualidade dos atendimentos e serviços prestados por terceiros à Unidade (DAHER, 2016).

\subsection{ANÁLISE DA MATRIZ SWOT (OU FOFA)}

Segundo Zimmerman (2015) a matriz SWOT (ou FOFA) é uma ferramenta utilizada para fazer análise de cenário, sendo usada como base para gestão e planejamento estratégico de uma organização. Entretanto, pode ser usada em qualquer tipo de análise de cenário devido a sua simplicidade, propiciando uma imagem do ambiente onde se encontra a instituição. Desse modo, foi utilizada a análise SWOT ou FOFA (Forças, Oportunidades, Fraquezas e Ameaças) que é uma maneira bastante eficiente de identificar os pontos fortes e fracos de uma organização, bem como examinar as oportunidades e as ameaças que poderão ser enfrentadas no seu ambiente de atuação.

Conforme o relatório de gestão de 2019, este ano correspondeu ao último do ciclo de Planejamento Estratégico 2016-2019. Dado o histórico protagonismo do Instituto e lançando seu olhar para o futuro, o Planejamento, à época de sua elaboração, trouxe como Visão exercer plenamente seu papel governamental como uma Instituição de referência no âmbito nacional e internacional em assistência, ensino e pesquisa oncológica buscando a excelência na elaboração de políticas públicas na prevenção e controle do câncer.

O Relatório de Gestão do INCA de 2019 evidencia a influência positiva ou negativa que o ambiente externo pode exercer sobre o Instituto, que deve empenhar esforços para potencializar as oportunidades e minimizar as ameaças externas e internas. A seguir através do Tabela 1, são apresentadas as principais oportunidades e ameaças identificadas: 
Tabela 1 - Oportunidades e Ameaças apresentadas no Relatório de Gestão 2019.

\begin{tabular}{|c|c|c|c|c|c|c|}
\hline \multirow{2}{*}{\multicolumn{2}{|c|}{$\begin{array}{l}\text { Implementação de } \\
\text { políticas públicas de saúde } \\
\text { com foco na promoção à } \\
\text { saúde e prevenção de } \\
\text { doenças e na conformação } \\
\text { das Redes de Atenção à } \\
\text { Saúde. }\end{array}$}} & \multicolumn{4}{|c|}{ OPORTUNIDADES } & \multirow[b]{2}{*}{$\begin{array}{l}\text { Esforço coletivo } \\
\text { da instituição na } \\
\text { detecção das } \\
\text { dificuldades dos } \\
\text { processos } \\
\text { internos e na } \\
\text { redefinição de } \\
\text { rumos e } \\
\text { prioridades. }\end{array}$} \\
\hline & & \multicolumn{2}{|c|}{$\begin{array}{l}\text { Aumento da } \\
\text { demanda pela } \\
\text { profissionalizaçã } \\
\text { o de gestores, de } \\
\text { sistemas e } \\
\text { serviços de saúde. }\end{array}$} & $\begin{array}{l}\text { Fortalecimento } \\
\text { do controle } \\
\text { social, refletindo } \\
\text { a demanda da } \\
\text { sociedade por } \\
\text { uma gestão } \\
\text { pública mais } \\
\text { transparente e } \\
\text { eficaz. }\end{array}$ & $\begin{array}{l}\text { Melhorias no } \\
\text { âmbito da } \\
\text { tecnologia da } \\
\text { informação, } \\
\text { ampliando o } \\
\text { acesso à } \\
\text { informação } \\
\text { interna. }\end{array}$ & \\
\hline \multicolumn{7}{|c|}{ AMEAÇAS } \\
\hline $\begin{array}{l}\text { O incremento } \\
\text { orçamentário } \\
\text { limitado pela taxa } \\
\text { oficial de inflação, } \\
\text { sendo inferior aos } \\
\text { reajustes aplicados } \\
\text { por concessionárias } \\
\text { públicas e outros } \\
\text { serviços. }\end{array}$ & $\begin{array}{l}\text { Cresc } \\
\text { despe } \\
\text { aumes } \\
\text { medic } \\
\text { alto ct } \\
\text { neces } \\
\text { incorp } \\
\text { novas } \\
\text { somac } \\
\text { cambi }\end{array}$ & $\begin{array}{l}\text { imento das } \\
\text { sas pelo } \\
\text { ato do uso de } \\
\text { amentos de } \\
\text { usto e pela } \\
\text { sidade de } \\
\text { oração de } \\
\text { tecnologias, } \\
\text { lo à flutuação } \\
\text { al. }\end{array}$ & $\begin{array}{l}\text { nún } \\
\text { cân } \\
\text { oca } \\
\text { prin }\end{array}$ & $\begin{array}{l}\text { ento do } \\
\text { ro de casos de } \\
\text { r no País, } \\
\text { onado, } \\
\text { palmente, } \\
\text { hecimento da } \\
\text { ação. }\end{array}$ & $\begin{array}{l}\text { Desigualdade no } \\
\text { acesso aos serviços } \\
\text { de saúde, em } \\
\text { particular aos } \\
\text { procedimentos de } \\
\text { média } \\
\text { complexidade, } \\
\text { impactando a } \\
\text { possibilidade de } \\
\text { diagnóstico precoce } \\
\text { de neoplasias. }\end{array}$ & $\begin{array}{l}\text { Déficit de pessoal, } \\
\text { dada a inexistência } \\
\text { de uma política } \\
\text { regular e ágil para } \\
\text { reposição de } \\
\text { servidores. }\end{array}$ \\
\hline
\end{tabular}

Fonte: Adaptado do Relatório de Gestão INCA 2019.

Segundo Daher (2016), o setor de Apoio Administrativo tem como visão alcançar maior eficiência no funcionamento das atividades de forma contribuir com os objetivos e metas estabelecidas pela Instituição. Para viabilizar o cumprimento de sua missão e visão, o setor desenvolve suas atividades em torno das legislações vigentes através dos macroprocessos identificados: gestão e fiscalização de contratos de serviços, gestão de protocolo e expedição de documentos e gestão predial.

$\mathrm{Na}$ avaliação dos pontos relacionados ao macroprocesso de gestão e fiscalização de contratos de serviços que compreendem o processo de planejamento de contratação, o processo de seleção dos fornecedores e o processo de gerenciamento do contrato de serviço. O processo de planejamento de Contratação retrata a caracterização do serviço que se quer contratar, o levantamento das

RC: 88625

Disponível em: https://www.nucleodoconhecimento.com.br/administracao/area-publica 
necessidades da Instituição, análise das legislações e normas vigentes e específicas sobre o objeto a contratar e por fim, elaboração do Plano de Trabalho que irá compor o Termo de Referência com as informações de todo o escopo do serviço demandado.

A seleção de fornecedores retrata todo o processo de contratação do serviço, que tem como objetivo final autorizar o funcionamento de novas empresas para prestação dos contratos de serviços no INCA, tendo como desafio principal alinhar todas as etapas para melhoria na qualidade da prestação dos serviços continuados, proporcionando maior eficiência na execução das atividades e na utilização dos recursos públicos.

O processo de gerenciamento dos contratos de serviços deve orientar os procedimentos operacionais das empresas contratadas e as atividades dos fiscais administrativos e técnicos de contratos, em consonância com as características e atribuições definidas em edital de contratação, bem como o desafio de assegurar a efetividade na prestação dos serviços em conformidade com a lei, tanto por ações preventivas, educativas, quanto punitivas. O setor em questão, o Serviço de Apoio Administrativo, é a área responsável pelo início do processo de contratação e posterior gestão e fiscalização de contratos de serviços continuados, os quais representam as atividades acessórias de apoio às atividades fins da Instituição.

Em consonância com as oportunidades e ameaças apontadas na tabela 1, e análise da bibliografia sobre o assunto foi construída a matriz SWOT (ou FOFA) do Serviço de Apoio Administrativo representada na Figura 2 abaixo. 
Figura 2 - Matriz SWOT (ou FOFA) do Serviço de Apoio Administrativo.
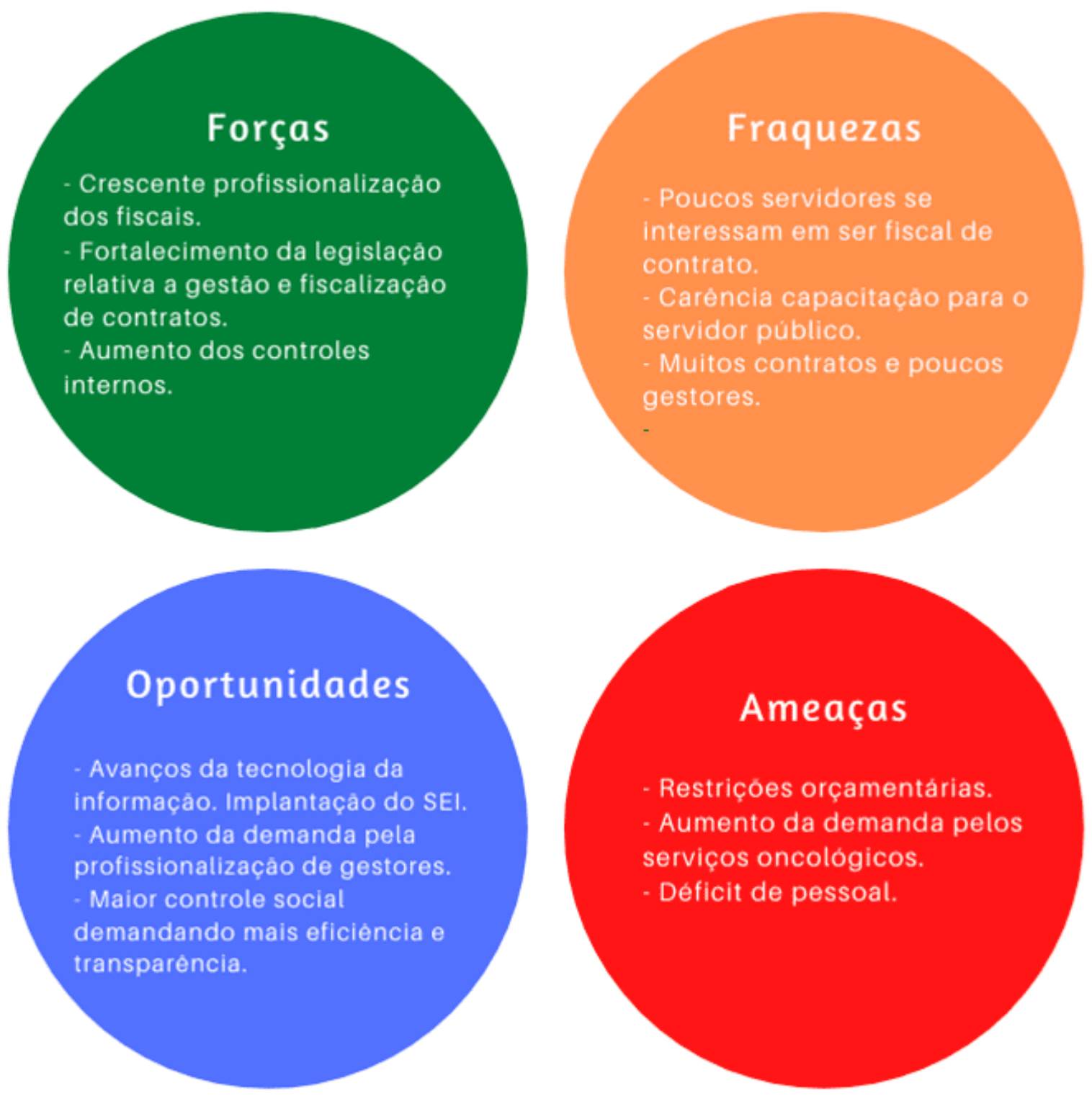

Fonte: Dados da pesquisa (2020).

\subsection{BALANCED SCORECARD APLICADO AO APOIO ADMINISTRATIVO}

Um indicador traduz certo aspecto de uma realidade de maneira quantitativa, de forma a tornar possível sua observação e avaliação como sua finalidade principal. Para Ferreira, Cassiolato e Gonzales (2009) é uma medida tanto quantitativa quanto

RC: 88625

Disponível em: https://www.nucleodoconhecimento.com.br/administracao/area-publica 
qualitativa, utilizada para organizar informações importantes dos elementos que compõem o objeto da observação.

Constitui-se em um recurso metodológico com a finalidade de informar a evolução do aspecto observado empiricamente. O Painel de Indicadores é formado por um conjunto de indicadores que traduzem os resultados alcançados quanto aos objetivos estratégicos.

No que tange a Administração Pública, é oportuno considerar os conceitos de efetividade, eficácia e eficiência na escolha de indicadores de desempenho. Ou seja, existem diversas tipologias de indicadores e esses três conceitos podem ser considerados os mais relevantes (JANNUZZI, 2002). Eficiência está relacionada com os produtos gerados por uma atividade, sendo eles bens ou serviços, com os custos dos insumos empregados para tal em um período de tempo determinado. Eficácia pode-se dizer que é o quanto das metas programadas foi alcançada, durante certo período de tempo, sem considerar os custos envolvidos. Finalmente, efetividade é a relação entre os resultados alcançados e os objetivos que motivaram a atuação institucional, entre o impacto previsto e o impacto real de uma atividade.

A escolha de um conjunto de indicadores adequados para monitorar o objeto avaliado (seja organização, departamento, processo, objetivo, iniciativa, programa, projeto, produto ou serviço) é essencial, tendo em vista que para a Administração Pública o tratamento e análise das informações geradas por estes indicadores são atividades que demandam esforços gerenciais. Considerando os conceitos de eficiência, eficácia e efetividade para obter um grupo de indicadores de desempenho da organização possibilita o balanceamento da avaliação no geral, evitando-se a análise de aspectos meramente relacionados ao processo ou análise apenas dos produtos ou impactos obtidos sem considerar a melhoria do processo como um todo (ZIMMERMAN, 2015).

Para Zimmerman (2015) as ações que deverão ser implementadas em curto e médio prazos a fim de garantir a concretização dos objetivos colocados no Mapa Estratégico, assim como diminuir o hiato entre o desempenho atual da organização e a situação que ser quer alcançar. Costumam ser representadas por projetos, mas não exclui ações isoladas como os atos normativos e/ou melhoria de processos.

Com base nos conceitos apontados acima e no Plano Estratégico do INCA 20202023, foi construída a Tabela 2 - Painel de Indicadores Balanced Scorecard para o Apoio Administrativo abaixo. 
Tabela 2: Painel de Indicadores BSC para o Apoio Administrativo.

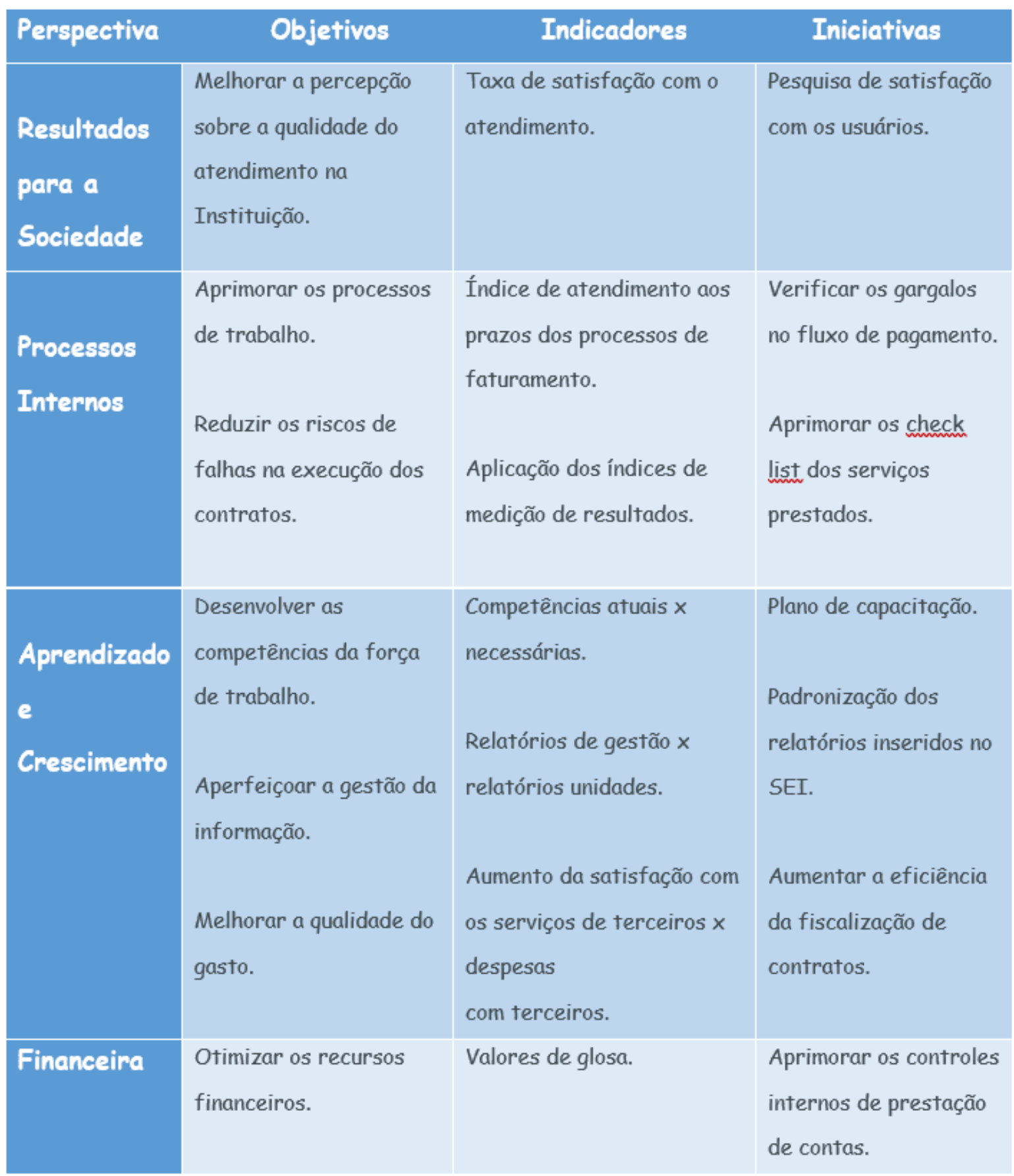

A importância da gestão e fiscalização de contratos administrativos é refletido pelo fato de que o somatório das despesas com serviços compromete mais de $50 \%$ do orçamento aplicado em custeio necessário para a manutenção das atividades finalísticas do Instituto. O aprimoramento do processo de fiscalização dos contratos de serviços permite a aplicação de penalidade (glosa) nas faturas dos fornecedores

$\mathrm{RC}: 88625$

Disponível em: https://www.nucleodoconhecimento.com.br/administracao/area-publica 
que não cumprem adequadamente todas as obrigações contratuais. Dessa forma, a fiscalização ao longo de 2019 desonerou o orçamento em $R$ \$ 9,57 milhões nos principais contratos vigentes gerenciados pela Coordenação de Administração-Geral (Relatório de Gestão INCA, 2019, p.77). Outrossim, a fiscalização realizada ao longo de 2018 gerou a economia de $R \$ 8,67$ milhões sobre a maior parte dos contratos vigentes (RELATÓRIO DE GESTÃO INCA, 2018, p. 61).

Levando em consideração que a Administração Pública não visa o lucro, a perspectiva financeira, ao invés de ser o objetivo final da instituição, é uma perspectiva essencial para sua sobrevivência e suporte ao cumprimento de sua função social. Por isso, entende-se que a perspectiva financeira deva sair do topo do BSC e ir para a base. Assim, um bom andamento dos objetivos financeiros cria condições para que haja uma melhoria dos objetivos ligados às pessoas e as atividades de aprimoramento da gestão.

Diversos autores, tais como Motta (2003) e Melgaço (2003) afirmam que, para as organizações públicas, a perspectiva financeira não é o objetivo final, mas sim um meio para obtenção de verbas necessárias para cumprir sua função social. Executar seu orçamento de forma competente e ampliar a captação de recursos são fatores fundamentais para tornar o órgão público sólido e apto a cumprir sua missão. Por este motivo, na administração pública a perspectiva financeira está focada na execução do orçamento e não no lucro como acontece na iniciativa privada.

As limitações da gestão de pessoas no serviço público se refletem no déficit de pessoal, dada a inexistência de uma política regular e ágil para reposição de servidores através de concurso público apontada no quadro de ameaças apresentado na matriz SWOT (ou FOFA) supracitada. No setor público é difícil reter talentos e renovar o quadro de pessoal. Por este motivo, capacitar o quadro de pessoal é importante e está incluída como objetivos estratégicos na perspectiva aprendizado e crescimento.

Segundo Marini (2002), a valorização do servidor é de grande importância para que o processo de modernização administrativa tenha êxito, pois a qualidade profissional dos servidores e sua motivação são pilares para se alcançar os outros objetivos. A sociedade atual estabelece o conhecimento como um dos principais fatores de produção. Sendo assim, para enfrentar as limitações impostas pela forte cultura burocrática dominante, é preciso estimular a capacidade empreendedora de seus colaboradores.

\section{CONSIDERAÇÕES FINAIS}

Esta pesquisa teve como objetivo geral apresentar as possibilidades de contribuição do Balanced Scorecard na gestão e fiscalização de contratos de serviços na área pública, através de um estudo de caso no INCA. Para tal, foi analisado o setor de 
Apoio Administrativo ligado a Coordenação de Administração Geral do Instituto, através da matriz SWOT (ou FOFA), as forças, fraquezas, oportunidades e ameaças. No momento seguinte foi elaborado sob a ótica do BSC indicadores de desempenho que podem ser utilizados pelos gestores de contratos de serviços continuados.

O BSC tem papel importante num modelo de gestão baseado em constante aprendizado, sendo uma ferramenta capaz de sistematizar a discussão. Neste sentido, o objetivo foi alcançado já que se vislumbrou um processo continuo de aperfeiçoamento numa área sensível do Instituto. Tendo em vista a crescente pressão sobre as organizações públicas, de atender melhor a sociedade e de realizar mais investimentos com menos recursos disponíveis, a implementação da gestão integrada e do planejamento estratégico pode ser uma importante oportunidade para a redução de custos, melhoria da qualidade e alcance dos resultados dessas organizações.

Por fim, verificou-se que se destacam como fatores de maior contribuição do BSC a eficiência na busca da modernização da gestão pública e o controle orçamentário, visto que os objetivos estratégicos, relacionados com a perspectiva orçamentária, devem estar atrelados aos resultados que irão contribuir para a cultura e a busca da eficiência, privilegiando as organizações públicas que demonstrem maior capacidade de gerir os seus gastos.

Esta pesquisa não esgota a discussão podendo estudos futuros serem realizados para o aprofundamento dos conhecimentos sobre a metodologia Balanced Scorecard e sua aplicação. Diversas áreas do próprio Instituto ou outras Instituições podem utilizar a metodologia BSC, tendo em vista a crescente necessidade dos órgãos públicos em aumentar sua eficiência na prestação de seus serviços à sociedade. A tendência de modernização do setor público favorece as diversas pesquisas que realizam análises sobre a adaptação de metodologias originalmente privadas para as instituições do setor público.

\section{REFERÊNCIAS}

ACKOFF, R. L. Planejamento empresarial. Rio de Janeiro: Coleção Administração e Gerência. 1976.

BRASIL. Constituição da República Federativa do Brasil de 1988. Disponível em: http://www.planalto.gov.br/. Acesso em: 15 de agosto de 2020.

BRASIL. Ministério da Saúde/Subsecretaria de Atenção Especializada a Saúde. Portaria SAES/MS № 1399, de 17 de Dezembro de 2019. Redefine os critérios e parâmetros referenciais para a habilitação de estabelecimentos de saúde na alta 
complexidade em oncologia no âmbito do SUS. Disponível em: https://www.inca.gov.br/. Acesso em: 15 de agosto de 2020.

BRASIL. Ministério da Saúde/Gabinete do Ministro. Portaria no 1.419, de 8 de junho de 2017. Disponível em: https://www.in.gov.br/. Acesso em: 15 de agosto de 2020.

BRASIL. Ministério do Planejamento, Desenvolvimento e Gestão/Secretaria de Gestão Instrução Normativa № 5, de 26 de Maio de 2017. Dispõe sobre as regras e diretrizes do procedimento de contratação de serviços sob o regime de execução indireta no âmbito da Administração Pública federal direta, autárquica e fundacional. Disponível em https://www.gov.br/compras/pt-br. Acesso em: 10 de setembro de 2020.

BRASIL. Presidência da República/Casa Civil - Subchefia para Assuntos Jurídicos. Lei no 8.691, de 28 de julho de 1993. Dispõe sobre o Plano de Carreiras para a área de Ciência e Tecnologia da Administração Federal Direta, das Autarquias e das Fundações Federais e dá outras providências. Disponível em:

http://www.planalto.gov.br/. Acesso em: 10 de setembro de 2020.

BRASIL. Tribunal de Contas da União. Portaria n. 297 de 14 de novembro de 2012. Dispõe sobre a fiscalização dos contratos de prestação de serviços terceirizados de natureza continuada no âmbito da Secretaria do Tribunal de Contas da União. Disponível em https://portal.tcu.gov.br/. Acesso em: 10 de setembro de 2020.

DAHER, Emilio Possidente. Diagnóstico e proposição de melhorias na gestão e fiscalização de contratos de serviços aplicados ao Instituto Nacional de Câncer José Alencar Gomes da Silva - INCA. 246 p. (Dissertação) Programa de PósGraduação em Administração, Universidade Federal Rural do Rio de Janeiro, RJ, 2016.

DE FREITAS, M.; MALDONADO, J. M. S. V. O pregão eletrônico e as contratações de serviços contínuos. Revista de Administração Pública, Volume 47, n. 5, pp. 1265-1281, 2013.

DRUCKER, P. Introdução à administração. São Paulo: Pioneira, 1998.

EISENHARDT, K.M. Building theories form case study research. Academy of Management. Review. New York, New York, v. 14 n. 4, 1989.

FERNANDES, M.E.R.; CARVALHO NETO, A. M. As práticas gerenciais frente aos principais desafios apontados pelas maiores empresas brasileiras na gestão de terceirizados. In: Encontro Nacional da Associação Nacional dos programas de Pós-graduação e Pesquisa em Administração, Brasília. ANPAD, 2005.

RC: 88625

Disponível em: https://www.nucleodoconhecimento.com.br/administracao/area-publica 
FERREIRA, H.; CASSIOLATO, M.; GONZALEZ, R. Uma experiência de desenvolvimento metodológico para avaliação de programas: o modelo lógico do programa segundo tempo. Texto para discussão. Rio de Janeiro: IPEA, 2009.

FREITAS, I. M. Balanced Scorecard: Um estudo de caso sobre o planejamento estratégico no Ministério Público do Distrito Federal e Territórios/ Roque Magno de Oliveira. - Brasília, 2016.

GALAS, E. S.; PONTE, V. M. R. O balanced scorecard e o alinhamento estratégico da tecnologia da informação: um estudo de casos múltiplos.

Revista Contabilidade e Finanças, São Paulo, n. 40, jan./ abr. 2006.

GIL, A. C. Métodos e técnicas de pesquisa social / Antonio Carlos Gil. - 6. ed. São Paulo : Atlas, 2008.

JANNUZZI, P. M. Indicadores para diagnóstico, monitoramento e avaliação de programas sociais no Brasil. Revista do Serviço Público. Rio de Janeiro, jan/fev, 2002.

KAPLAN, R. S., NORTON, D. P., A Estratégia em Ação: Balanced Scorecard. São Paulo: Campus, 1997.

Alinhamento: Usando o Balanced Scorecard para criar sinergias corporativas. Rio de Janeiro: Elsevier, 2006.

KRAEMER, M.E. P, As Múltiplas Funções do Balanced Scorecard. S.P; 19 de Dezembro de 2004.

LOBATO, D. M. Administração Estratégica. Rio de Janeiro. Editoração Ed Ltda, 2000.

MARINI, C. O contexto contemporâneo da administração pública na América Latina. Revista do Serviço Público, Brasília, 2002.

MARQUES, R.A. Avaliação dos resultados da utilização dos critérios de excelência do PNQ em instituições de P\&D. 2004. 149f. Dissertação (Mestrado Profissional em Gestão da Qualidade Total) - Departamento de Engenharia Mecânica, Universidade Estadual de Campinas, Goiânia. 2004.

MATUS, C. Política, Planejamento e Governo (1 e 2). Brasília. IPEA, 1993.

MEIRELLES, H. L. Direito administrativo brasileiro. 29 ed. São Paulo: Malheiros, 2004. 
MELGAÇO, M. M. Avaliando o desempenho de uma secretaria de governo. Banas Qualidade, São Paulo, 2003.

MENDES, G. H. de S. Administração estratégica / Glauco Henrique de Sousa Mendes. - Florianópolis : Departamento de Ciências da Administração / UFSC, 2015.

MINTZBERG, H.; AHLSTRAND, B.; LAMPEL, J. Safári de Estratégia. Porto Alegre: Bookman, 2000.

MOREIRA, F. F.; SEDRANI, L. G. M. e LIMA, R. C. O que é o Balanced Scorecard?: A evolução do BSC, de um sistema de indicadores para um modelo de gestão estratégica, 2005.

MOTTA, R. Balanced scorecard em organizações públicas e sem fins lucrativos um sistema de medição para alinhar e gerenciar o sucesso da estratégia. CONGRESSO BRASILEIRO DA QUALIDADE E PRODUTIVIDADE, 13. Rio de Janeiro, 2003.

NIVEN, P. R. Balanced scorecard- passo a passo: elevando o desempenho e mantendo resultados. Rio de Janeiro: Qualitymark, 2005.

OLIVEIRA, G. A. G. Elaboração de Termos de Referência para Contratação de Bens e Serviços / Gisele Aparecida Gonçalves de Oliveira; revisão, Luiz Matos. -Brasília: Enap, 2017.

PINTO, A. L. O Planejamento Estratégico na Administração Pública Brasileira: rumos e perspectivas. Cadernos FUNDAP, São Paulo, ano 2, no 4, p. 4-13, junho de 1982.

PLANO ESTRATÉGICO INCA 2020-2023. Instituto Nacional de Câncer José Alencar Gomes da Silva - Rio de Janeiro, INCA, 2020.

PRAHALAD, C. K.; HAMEL, G. Competindo pelo Futuro. Rio de Janeiro: Elsevier, Campus, 23를ำ̧̃ão, 2005.

RELATÓRIO DE GESTÃO INCA 2019. Instituto Nacional de Câncer José Alencar Gomes da Silva - Rio de Janeiro, INCA, 2020.

\section{Instituto Nacional de Câncer José}

Alencar Gomes da Silva - Rio de Janeiro, INCA, 2019.

SOUZA, A.C.S. de; REZENDE, D.A.; HARDT, C. Estratégia, planejamento de municípios e gestão metropolitana. RAI - Revista de Administração e Inovação, São Paulo, v. 4, n. 1, p. 21-39, 2007. 
TROSA, S. Gestão pública por resultados: quando o Estado se compromete. Rio de Janeiro: Revan, 2001.

VERGARA, S. C. Projetos e relatórios de Pesquisa em Administração. 16ª ed. São Paulo: Atlas, 2016.

YIN, Robert K. Estudo de caso - planejamento e métodos. 2ª ed. Porto Alegre: Bookman,2001.

ZADSZNAJDER, L. Formação em Planejamento Estratégico, 1989.

ZIMMERMAN, F. Gestão da Estratégia com o uso do BSC/ Fábio Zimmerman; revisão e adaptação, Alexandre Laval Silva e Carlos Eduardo Penante D'Ávila Uchôa.-- Brasília: ENAP, 2015.

Enviado: Maio, 2021.

Aprovado: Junho, 2021. 